\section{JURNAL EKONOMI EFEKTIF}

ISSN : $2622-8882$, E-ISSN : 2622-9935

Jurnal Ekonomi Efektif, Vol. 3, No. 4, Juli 2021

@Prodi Manajemen Fakultas Ekonomi Universitas

Pamulang

\title{
PENGARUH DISPLAY PRODUK TERHADAP KEPUTUSAN PEMBELIAN PADA PT. BINA BARU DI JATI ASIH BEKASI
}

\author{
Indri Lastriyani ${ }^{1 *}$, Laely Purnamasari ${ }^{2}$ \\ STKIP PGRI Sukabumi, Sukabumi, Jawa Barat, Indonesia \\ indrilastriyani@stkippgrisukabumi.ac.id ${ }^{1 *}$, \\ laelypurnamasari@stkippgrisukabumi.ac.id ${ }^{2}$
}

Manuskrip: Mei -2021 Ditinjau: Mei -2021; Diterima: Juni-2021; Online: Juli-2021; Diterbitkan: Juli-2021

\begin{abstract}
ABSTRAK
Penelitian ini bertujuan untuk mengetahui pengaruh display produk terhadap keputusan pembelian pada PT. Bina Baru di Jati Asih Bekasi. Metode yang digunakan adalah explanatory research dengan sampel sebanyak 96 responden. Teknik analisis menggunakan analisis statistik dengan pengujian regresi, korelasi, determinasi dan uji hipotesis. Hasil penelitian ini variabel display produk diperoleh nilai rata-rata skor sebesar 3,403 dengan kriteria baik. Variabel keputusan pembelian diperoleh nilai rata-rata skor sebesar 3,821 dengan kriteria baik. Display produk berpengaruh positif dan signifikan terhadap keputusan pembelian dengan nilai persamaan regresi $Y=9,067+0,856 X$, dan nilai koefisien korelasi 0,769 atau memiliki tingkat hubungan yang kuat dengan nilai determinasi $59,1 \%$. Uji hipotesis diperoleh signifikansi 0,000 $<0,05$.
\end{abstract}

Kata Kunci: Display Produk, Keputusan Pembelian

\begin{abstract}
This study aims to determine the effect of product displays on purchasing decisions at PT. Bina Baru in Jati Asih Bekasi. The method used is explanatory research with a sample of 96 respondents. The analysis technique uses statistical analysis with regression testing, correlation, determination and hypothesis testing. The results of this study the product display variable obtained an average score of 3.403 with good criteria. The purchase decision variable obtained an average score of 3.821 with good criteria. Product display has a positive and significant effect on purchasing decisions with a regression equation value of $Y=9.067+$ $0.856 \mathrm{X}$, and a correlation coefficient value of 0.769 or has a strong level of relationship with a determination value of 59.1\%. Hypothesis testing obtained a significance of $0.000<0.05$.
\end{abstract}

Keywords: Product Display, Purchase Decision 


\section{PENDAHULUAN}

\section{A. Latar Belakang}

Pemasaran merupakan salah satu kegiatan-kegiatan pokok yang dilakukan oleh pengusaha dalam usahanya untuk mempertahankan kelangsungan hidupnya untuk berkembang dan mendapatkan laba. Sebuah perusahaan dikatakan berhasil menjalankan fungsinya apabila mampu menjual produknya pada konsumen dan memperoleh profit semaksimal mungkin. Konsumen sebagai salah satu element yang memegang peranan penting dimana dari waktu kewaktu mereka semakin kritis dalam menyikapi suatu produk maupun jasa yang ditawarkan.

Perilaku konsumen merupakan suatu tindakan yang diambil konsumen dalam melaksanakan keputusan untuk membeli barang atau jasa. Maka dari itu perusahaan harus dapat mengambil tindakan yang tepat dalam memotivasi konsumen untuk memenuhi produk yang dihasilkan dan dapat menciptakan keputusan pembelian bagi konsumen. Dalam usaha penataan barang agar konsumen mau berkunjung kembali, maka ada beberapa faktor yang mempengaruhinya diantaranya adalah kualitas hubungan yang baik dengan setiap konsumennya, dan kemampuan perusahaan dalam menangani keluhan dari pelanggan. Hubungan ini sendiri dapat menimbulkan keputusan pembelian pelanggan dan untuk membangun suatu hubungan yang lebih dekat. Dengan menciptakan komunikasi dua arah sehingga dapat menimbulkan kepercayaan dan keputusan pembelian hingga keputusan pembelian yang dilakukan oleh konsumen.

Bisnis dunia fashion saat ini telah berkembang besar di Indonesia. Mulai dari fashion anak-anak sampai fashion orang dewasa sangat banyak kita jumpai disemua modern market ataupun di department store. Masuknya merek fashion internasional ke Indonesia membuat Indonesia semakin modern dalam dunia fashion, dan produk Indonesiapun tidak kalah dalam persaingan merebut pasar dunia fashion di Indonesia.

Di Indonesia bisnis fashion merek internasional banyak dimonopoli oleh perusahaan besar seperti MAP Group, GAP Group dan sebagainya. Namun produk fashion Indonesia tetap bertahan karena masih sangat banyak dicintai oleh masyarakat Indonesia. Semakin banyaknya mall ataupun modern market yang beroperasional di Indonesia maka semakin banyak pula merekfashion internasional masuk ke Indonesia, sehingga para pengusaha semakin memperketat daya saing agar produk atau merek mereka semakin laku dan diminati dipasaran. Maka untuk brand atau merek produk fashion lokal harus siap menghadapinya dan mampu bersaing.

PT. Bina Baru adalah perusahaan retail yang mendistribusikan pakaian sehari-hari dan pakaian tidur untuk semua usia mulai dari anak-anak, dewasa, wanita hingga lakilaki, serta menyediakan berbagai ukuran serta dengan varian merek dan bahan-bahan yang berkualitas. Benvica sleepwear saat ini mempunyai 15 toko yang tersebar di Jabodetabek, dari semua toko yang dimiliki oleh benvica terdapat beberapa toko yang penjualannya mengalami penurunan dan tidak sampai dengan target yang telah ditetapkan oleh manajemen PT. Bina Baru.

Dalam operasionalnya benvica memiliki cara tersendiri yang dapat menarik minat konsumen atau pembeli agar mau memakai atau membeli produknya, untuk itu para pramugiana atau SPG (Sales Promotion Girl) harus diberikan pengajaran atau ilmu yang baik dalam melaksanakan opersional, seperti tehnik pendisplayan atau penataan barang. Permasalahan yang sering terjadi adalah kurang berminatnya konsumen atau pelanggan untuk memiliki barang yang kita jual dikarenakan permasalahan- permasalahan yang seharusnya bisa dihindari agar konsumen tertarik untuk membeli produk kita tersebut.

Untuk menarik konsumen agar tertarik masuk dan membeli maka hal yang pertama harus diperhatikan adalah display produk. Menurut Sopiah dan Syiahbudhin 
(2008) display adalah usaha yang dilakukan untuk menata barang yang mengarahkan pembeli agar tertarik untuk melihat dan membeli. Display barang sangat penting dilakukan, Karena display yang baik akan menimbulkan minat pelanggan untuk membelinya Permasalahan yang dibahas disini adalah display produk yang belum optimal dikarenakan lokasi dan ukuran toko yang sangat kecil sehingga sulit untuk memaksimalkan dalam pendisplayan, oleh karena itu maka harus menggunakan tehnik dalam pendisplayan agar dapat terlihat lebih menarik dan untuk menciptakan keputusan pembelian bagi konsumen yang melihatnya.Menurut Kotler dan Keller (2009: 240) keputusan pembelian adalah keputusan para konsumen membentuk preferensi atas merek-merek yang ada dalam kumpulan pilihan, konsumen tersebut juga dapat membentuk niat untuk membeli merek yang paling disukai.

Berdasarkan latar belakang permasalahan diatas maka penulis tertarik untuk melakukan penelitian mengenai, "Pengaruh Display Produk Terhadap Keputusan Pembelian di PT. Bina Barudi Jati Asih Bekasi”.

\section{B. Rumusan Masalah}

1. Bagaimana display produk pada PT. Bina Baru di Jati Asih Bekasi ?.

2. Bagaimana keputusan pembelian pada PT. Bina Baru di Jati Asih Bekasi ?.

3. Adakah pengaruh antara display produk terhadap keputusan pembelian pada PT. Bina Baru di Jati Asih Bekasi ?.

\section{Tujuan Penelitian}

1. Untuk mengetahui kondisi display produk pada PT. Bina Baru di Jati Asih Bekasi.

2. Untuk mengetahui kondisi keputusan pembelian pada PT. Bina Baru di Jati Asih Bekasi.

3. Untuk mengetahui pengaruh antara display produk terhadap keputusan pembelian pada PT. Bina Baru di Jati Asih Bekasi.

\section{TINJAUAN PUSTAKA}

\section{Display produk}

Yang dimaksud display menurut Sopiah dan Syiahbudhin (2008: 238) adalah usaha yang dilakukan untuk menata barang yang mengarahkan konsumen agar tertarik untuk melihat dan membeli

\section{Keputusan pembelian}

Yang dimaksud keputusan pembelian menurut Kotler dan Keller (2012:264) adalah keputusan para konsumen membentuk preferensi atas merek- merek yang ada dalam kumpulan pilihan, konsumen tersebut juga dapat membentuk niat untuk membeli merek yang disukai.

\section{METODE PENELITIAN}

\section{Populasi} Bekasi

Populasi dalam penelitian ini berjumlah 96 responden PT. Bina Baru di Jati Asih

\section{Sampel}

Teknik pengambilan sampling dalam penelitian ini adalah sampel jenuh, dimana semua anggota populasi dijadikan sebagai sampel. Dengan demikian sampel dalam penelitian ini sampel yang digunakan berjumlah 96 responden. 


\section{Jenis Penelitian}

Jenis penelitian yang dipakai adalah asosiatif, dimana tujuannya adalah untuk mengetahui atau mencari keterhubungan antara variabel independen terhadap variabel dependennya

\section{Metode Analisis Data}

Dalam menganalisis data digunakan uji validitas, uji reliabilitas, analisis regresi linier sederhana, analisis koefisien korelasi, analisis koefisien determinasi dan pengujian hipotesis.

\section{HASIL PENELITIAN}

\section{Analisis Deskriptif}

Pada pengujian ini digunakan untuk mengetahui skor minimum dan maksimum skor tertinggi, ratting score dan standar deviasi dari masing-masing variabel. Adapun hasilnya sebagai berikut:

Tabel 1. Hasil Analisis Descriptive Statistics

Descriptive Statistics

\begin{tabular}{lr|r|r|r|r} 
& N & Minimum & Maximum & Mean & Std. Deviation \\
\hline Display Produk & 96 & 28 & 44 & 34.03 & 3.785 \\
\hline Keputusan Pembelian & 96 & 29 & 49 & 38.21 & 4.215 \\
\hline Valid N (listwise) & 96 & & & & \\
\hline
\end{tabular}

Display produk diperoleh varians minimum sebesar 28 dan varians maximum 44 dengan ratting score sebesar 3,403 dengan standar deviasi 3,785. Skor ini termasuk pada rentang sakala 3,40-4,19 dengan kriteria baik atau setuju.

Keputusan pembelian diperoleh varians minimum sebesar 29 dan varians maximum 49 dengan ratting score sebesar 3,821 dengan standar deviasi 4,215. Skor ini termasuk pada rentang sakala 3,40 - 4,19 dengan kriteria baik atau setuju.

\section{Analisis Verifikatif}

Pada analisis ini dimaksudkan untuk mengetahui pengaruh variabel independen terhadap variabel dependen. Adapun hasil pengujian sebagai berikut:

\section{a. Analisis Regresi Linier Sederhana}

Uji regresi ini dimaksudkan untuk mengetahui perubahan variabel dependen jika variabel independen mengalami perubahan. Adapun hasil pengujiannya sebagai berikut:

\begin{tabular}{|c|c|c|c|c|c|c|}
\hline \multirow{3}{*}{\multicolumn{2}{|c|}{ Model }} & \multicolumn{3}{|c|}{ Coefficients $^{\mathrm{a}}$} & \multirow[b]{3}{*}{$\mathrm{t}$} & \multirow[b]{3}{*}{ Sig. } \\
\hline & & \multicolumn{2}{|c|}{$\begin{array}{c}\text { Unstandardized } \\
\text { Coefficients }\end{array}$} & \multirow{2}{*}{$\begin{array}{c}\text { Standardized } \\
\text { Coefficients } \\
\text { Beta } \\
\end{array}$} & & \\
\hline & & $\mathrm{B}$ & Std. Error & & & \\
\hline 1 & (Constant) & 9.067 & 2.514 & & 3.606 & .001 \\
\hline & Display Produk & .856 & .073 & .769 & 11.661 & .000 \\
\hline
\end{tabular}

a. Dependent Variable: Keputusan Pembelian

Berdasarkan hasil pengujian pada tabel di atas, diperoleh persamaan regresi $\mathrm{Y}$ $=9,067+0,856 X$. Dari persamaan tersebut dijelaskan sebagai berikut:

1) Konstanta sebesar 9,067 diartikan jika display produk tidak ada, maka telah terdapat nilai keputusan pembelian sebesar 9,067 point.

2) Koefisien regresi display produk sebesar 0,856 , angka ini positif artinya setiap ada peningkatan display produk sebesar 0,856 point maka keputusan pembelian juga akan mengalami peningkatan sebesar 0,856 point. 


\section{b. Analisis Koefisien Korelasi}

Analisis koefisien korelasi dimaksudkan untuk mengetahui tingkat kekuatan hubungan dari variabel independen terhadap variabel dependen. Adapun hasil pengujian sebagai berikut:

Tabel 3. Hasil Pengujian Koefisien Korelasi Display produk Terhadap Keputusan pembelian.

\section{Correlations $^{\text {b }}$}

\begin{tabular}{llr|r} 
& & $\begin{array}{r}\text { Display } \\
\text { Produk }\end{array}$ & \multicolumn{1}{c}{$\begin{array}{r}\text { Keputusan } \\
\text { Pembelian }\end{array}$} \\
\hline Display Produk & Pearson Correlation & 1 & $.769^{* *}$ \\
\cline { 2 - 4 } & Sig. (2-tailed) & & .000 \\
\hline Keputusan Pembelian & Pearson Correlation & $.769^{* *}$ & 1 \\
\cline { 2 - 4 } & Sig. (2-tailed) & .000 & \\
\hline
\end{tabular}

**. Correlation is significant at the 0.01 level (2-tailed).

b. Listwise $\mathrm{N}=96$

Berdasarkan hasil pengujian diperoleh nilai korelasi sebesar 0,769 artinya display produk memiliki hubungan yang kuat terhadap keputusan pembelian.

\section{c. Analisis Koefisien Determinasi}

Analisis koefisien determinasi dimaksudkan untuk mengetahui besarnya persentase pengaruh dari variabel independen terhadap variabel dependen. Adapun hasil pengujian sebagai berikut:

Tabel 4. Hasil Pengujian Koefisien Determinasi Display produk Terhadap Keputusan pembelian.

Model Summary

\begin{tabular}{|c|c|c|c|c|}
\hline \multicolumn{5}{|c|}{ Model Summary } \\
\hline Model & $\mathrm{R}$ & R Square & $\begin{array}{l}\text { Adjusted R } \\
\text { Square }\end{array}$ & $\begin{array}{l}\text { Std. Error of the } \\
\text { Estimate }\end{array}$ \\
\hline 1 & $.769^{\mathrm{a}}$ & .591 & .587 & 2.709 \\
\hline
\end{tabular}

Berdasarkan hasil pengujian diperoleh nilai determinasi sebesar 0,591 artinya display produk memiliki kontribusi pengaruh sebesar 59,1\% terhadap keputusan pembelian, sedangkan sisanya sebesar 39,9\% dipengaruhi oleh faktor lain yang tidak dilakukan penelitian.

\section{d. Uji Hipotesis}

Pengujian hipotesis dengan uji t digunakan untuk mengetahui hipotesis mana yang diterima.

Rumusan hipotesis: Terdapat pengaruh yang signifikan antara display produk terhadap keputusan pembelian.

Tabel 5. Hasil Uji Hipotesis Display produk Terhadap Keputusan pembelian.

\begin{tabular}{|c|c|c|c|c|c|c|}
\hline \multirow{3}{*}{\multicolumn{2}{|c|}{ Model }} & \multicolumn{3}{|c|}{ Coefficients $^{\mathrm{a}}$} & \multirow[b]{3}{*}{$\mathrm{t}$} & \multirow[b]{3}{*}{ Sig. } \\
\hline & & \multicolumn{2}{|c|}{$\begin{array}{l}\text { Unstandardized } \\
\text { Coefficients }\end{array}$} & \multirow{2}{*}{$\begin{array}{c}\text { Standardized } \\
\text { Coefficients } \\
\text { Beta } \\
\end{array}$} & & \\
\hline & & $\mathrm{B}$ & Std. Error & & & \\
\hline 1 & (Constant) & 9.067 & 2.514 & & 3.606 & .001 \\
\hline & Display Produk & .856 & .073 & .769 & 11.661 & .000 \\
\hline
\end{tabular}

a. Dependent Variable: Keputusan Pembelian

Berdasarkan hasil pengujian pada tabel di atas, diperoleh nilai $\mathrm{t}$ hitung $>\mathrm{t}$ tabel atau $(11,661>1,986)$, dengan demikian hipotesis yang diajukan bahwa terdapat pengaruh yang signifikan atara display produk terhadap keputusan pembelian diterima. 


\section{Pembahasan Hasil Penelitian}

\section{Kondisi Jawaban Responden Variabel Display produk}

Berdasarkan jawaban responden, variabel display produk diperoleh ratting score sebesar 3,403 berada di rentang skala 3,40-4,19 dengan kriteria baik atau setuju.

\section{Kondisi Jawaban Responden Variabel Keputusan pembelian}

Berdasarkan jawaban responden, variabel keputusan pembelian diperoleh ratting score sebesar 3,821 berada di rentang skala 3,40 - 4,19 dengan kriteria baik atau setuju.

\section{Pengaruh Display produk Terhadap Keputusan pembelian}

Display produk berpengaruh signifikan terhadap keputusan pembelian dengan persamaan regresi $\mathrm{Y}=9,067+0,856 \mathrm{X}$, nilai korelasi sebesar 0,769 atau memiliki hubungan yang kuat dengan kontribusi pengaruh sebesar 59,1\%. Pengujian hipotesis diperoleh nilai t hitung $>\mathrm{t}$ tabel atau $(11,661>1,986)$. Dengan demikian hipotesis yang diajukan bahwa terdapat berpengaruh signifikan antara display produk terhadap keputusan pembelian diterima.

\section{KESIMPULAN DAN SARAN}

\section{Kesimpulan}

a. Variabel display produk diperoleh ratting score sebesar 3,403 berada di rentang skala 3,40 - 4,19 dengan kriteria baik atau setuju.

b. Variabel keputusan pembelian diperoleh ratting score sebesar 3,821 berada di rentang skala 3,40 - 4,19 dengan kriteria baik atau setuju.

c. Display produk berpengaruh signifikan terhadap keputusan pembelian dengan persamaan regresi $\mathrm{Y}=9,067+0,856 \mathrm{X}$, nilai korelasi sebesar 0,769 atau kuat dan kontribusi pengaruh sebesar 59,1\% sedangkan sisanya sebesar 39,9\% dipengaruhi faktor lain. Uji hipotesis diperoleh nilai t hitung > t tabel atau $(11,661>1,986)$.

\section{Saran}

a. Perusahaan harus lebih meningkatkan kembali display agar lebih kreatif dan inovatif sehingga dapat lebih menarik perhatian pelanggan agar melakukan pembelian.

b. Kperusahaan sebaiknya memberikan informasi yang lebih tentang produk yang dijual dikarenakan masih banyak pelanggan yang mencari tahu sendiri tentang informasi produk yang akan dibeli, dan akan sangat membatu proses keputusan pembelian jika perusahaan memberikan secara detail dan jelas tentang infromasi produknya.

c. Perusahaan sebaiknya memindahkan lokasi 493ook ke tempat yang lebih strategis lagi dikarenakan untuk mendapatkan lebih banyak lagi konsumen baru yang berbelanja.

d. Perusahaan sebaiknya menyewa 493ook yang lebih besar lagi dari 493ook yang sekarang karena untuk memaksimalkan dalam pendisplayan produk yang dijual agar lebih terhihat menarik dan membuat konsumen nyaman dalam berbelanja.

\section{DAFTAR PUSTAKA}

Abdullah, M (2014) Manajemen dan Evaluasi Keputusan pembelian, Yogyakarta: Penerbit Aswaja Pressindo.

Algifari. (2015). "Analisis Regresi untuk Bisnis dan Ekonomi”. Yogyakarta: BPFE.

Arikunto, Suharsimi (2014). "Prosedur Penelitian Suatu Pendekatan Praktek". Jakarta: Rineka Cipta. 
Bashu Swastha dan T. Handoko (2015) Manajemen Pemasaran Moderen, Yogyakarta: BPFE.

Basu Swastha Dharmmesta. (2014). Manajemen Pemasaran. BPFE: Yogyakarta. Buchari Alma. 2014. Manajemen pemasaran dan Pemasaran Jasa. Edisi Revisi.

Bilson Simamora (2016) Panduan Riset Prilaku Konsumen, Jakarta: PT. Gramedia Pustaka.

Fandy Tjiptono (2017), Serivce Quality and Satisfiation. Jakarta: Edisi tiga. Andi.

Freddy Rangkuti (2016) Strategi Promosi Yang Kreatif, Edisi Pertama, Cetakan Pertama Jakarta: Gramedia Pustaka Utama.

Haque, M. G., Nurjaya, N., Affandi, A., Erlangga, H., \& Sunarsi, D. (2021). Micro Financial Sharia Non-bank Strategic Analysis: a Study at BMT Beringharjo, Yogyakarta. Budapest International Research and Critics Institute (BIRCI-Journal): Humanities and Social Sciences, 4(2), 1677-1686.

Imam Ghozali (2017). "Aplikasi Analisis Multivariate Dengan Program SPSS”. Edisi Kelima. Semarang: Badan Penerbit Undip.

Istijanto (2014) “Riset Sumber Daya Manusia”. Jakarta: PT. Gramedia Pustaka

Jasmani, J., \& Sunarsi, D. (2020). The Influence of Product Mix, Promotion Mix and Brand Image on Consumer Purchasing Decisions of Sari Roti Products in South Tangerang. PINISI Discretion Review, 1(1), 165-174.

Kasmad, K., Mustakim, M., \& Sunarsi, D. (2020). Increasing Community School Interest Through Service Quality, Prices and Promotion in Vocational High Schools. Journal of Educational Science and Technology (EST), 6(2).

Kharis, Ismu Fadli (2011). "Studi Mengenai Impulse Buying dalam Penjualan Online”. Semarang : Skripsi Universitas Diponegoro

Kotler dan Amstrong (2017), Prinsip-prinsip Pemasaran. Edisi Kedua Belas”. Jilid Satu. Jakarta: Erlangga.

Lupiyoadi (2016) Manajemen Pemasaran Jasa, Edisi 4, Jakarta: Salemba Empat.

Philip Kotler (2017) Manajemen Pemasaran, Edisi Keempat Belas, Jakarta: PT. Indeks.

Phipil Kotler dan Kevin Keller (2017) Manajemen Pemasaran, Edisi Kedua Belas, Jilid Satu, Jakarta: Erlangga.

Rao, Purba, (2012). “Measuring Consumer Perceptions Through Factor Analysis”, The Asian.

Santoso, Singgih (2015). "Menguasai Statistik Multivariat". Jakarta: PT Elex Media Komputindo.

Sudjana (2014) “Metode Statistika”, Bandung: Tarsido.

Sugiyono (2017), "Metode Penelitian Administrasi : dilengkapi dengan Metode $R \&$ D”. Bandung: Alfabeta.

Suhartanto (2014). “Metode Riset Pemasaran”. Bandung: Alfabeta

Susanti, N., \& Jasmani, J. (2020). The Influence of Product Quality and Service Quality on Customer Satisfaction at Mitra 10 in Depok. Jurnal Office, 5(2), 75-84.

Y Kadarusman, et al. (2020). Pengaruh Strategi Penetapan Harga Terhadap Peningkatan Jumlah Siswa Pada SMK PGRI Balaraja. JS (JURNAL SEKOLAH) 4 (3), 213-221 